\title{
THE CONDITION OF VOLUMETRIC AND OSMOREGULATORY FUNCTION OF THE KIDNEYS IN TOXICEMIA OF PURULENT-SEPTIC GENESIS IN PATIENTS WITH DIABETES MELLITUS
}

DOI: 10.36740/WLek202004120

\author{
Viktor M. Konovchuk, Sergiy V. Kushnir, Andriy V. Andrushchak, Iryna I. Iliuk, Petro V. Moroz \\ THE HIGHEST STATE INSTITUTION OF UKRAINE "BUKOVYNA STATE MEDICAL UNIVERSITY", CHERNIVTSI, UKRAINE
}

\begin{abstract}
The aim of the study is to investigate the state of volumetric and osmoregulatory function of the kidneys in diabetes complicated by the syndrome of the endogenous intoxication of purulent-septic genesis.

Materials and methods: The study group was consisted of patients with insulin-dependent diabetes mellitus with complicated syndrome of the endogenous intoxication of purulent-septic genesis (CSDI).

Results: The starting indices of volumetric and osmoregulatory function of the kidneys in patients with INCs complicated by the endogenous intoxication of purulent-septic genesis (CEI GHG) syndrome are characterized by the values of the inhibition of the volumorregulatory (by the clearance of sodium by $11 \%, \mathrm{p}<0.05$ ) and the activation of the osmoregulatory osmotically active substances by $23 \%, p<0.05)$ renal function. The volume increasing of the extracellular space by the Ringer solution activates the volumetric and osmoregulatory function of the kidneys, respectively, in patients with NSCL at $162 \pm 27.1 \%(\Delta, p<0.05)$ and $138 \pm 48.3 \%(\Delta, p<0.05)$, and at INCS complicated CEE GHS by $260 \pm 47.8 \%(\Delta, p<0.05)$ and $147 \pm 46.9 \%(\Delta, p<0.05)$.

Conclusions: The low-level isotonic loads with Ringer's solution initiate the same direction of change in indices of volumetric and osmoregulatory function of the kidneys in patients with systemic inflammatory response syndrome and diabetes mellitus with complicated endogenous intoxication syndrome of purulent-septic genesis and show dissociative hyper reactivity of the volumorregulatory function in relation to the osmoregulatory one.
\end{abstract}

KEY WORDS:Volumetric and osmoregulatory function of the kidneys, insulin-dependent diabetes mellitus, endogenous intoxication syndrome of purulent-septic genesis

Wiad Lek. 2020;73(4):733-736

\section{INTRODUCTION}

The course of diabetes mellitus limits the reserves of mechanisms for maintaining homeostasis and their compensatory opportunities, especially under the conditions of attaching additional adverse systemic factors [1-2].

One of them is endogenous toxemia of purulent-septic genesis [3].

Endotoxicosis is a complex multifactorial process that is initiated by primary alteration of tissues and gets a continuation in the form of phase changes that are transformed into a typical pathogenetic process [4]. Among the factors of endogenous intoxication are usually: microorganisms and their products of life, bacterial exo- and endotoxins, intermediate and end-products of normal metabolism (in excessive concentrations), components of organ, fabric, cellular and integrative regulatory systems (in pathologically high concentrations), products pathological metabolism, toxic substances of intestinal origin [5]. They are the leading factors of secondary alteration and predetermine the diversity of endotoxicosis (neuro, cardio, hepatotoxic, hematopoietic, nephrotoxic activity), which forms the spectrum of polyorganic damage [6].

The ability for activating processes of free radical oxidation and apoptosis, damage the endothelium and create a cytolytic effect, inhibit ribosomal and mitochondrial synthesis, destabilize lysosomes are in the basis of the organotropic action. The complex clinical situations and questions arise subject to the course of diabetes, in particular the degree of damage to various organs and systems in combination with endotoxicosis [7]. One of them is the determination of the state of homeostatic renal function when combined with diabetes mellitus with toxemia of purulent-septic origin.

\section{THE AIM}

The goal of the study is to investigate the state of volumetric and osmoregulatory function of the kidneys in diabetes mellitus complicated with endogenous intoxication syndrome of purulent-septic genesis.

\section{MATERIALS AND METHODS}

The study is opened, randomized, prospective and controlled. The study group is consisted of patients with insulin-dependent diabetes mellitus (IDDM) with complicated endogenous intoxication syndrome of purulent-septic genesis (CPSG). Inclusion criteria: IDDM, age - $42-65$ 
Table I. Investigate the state of volumetric and osmoregulatory function of the kidneys in diabetes complicated by the syndrome of the endogenous intoxication of purulent-septic genesis.

\begin{tabular}{|c|c|c|c|c|}
\hline \multirow{2}{*}{ Index } & \multicolumn{2}{|c|}{$\operatorname{SSIR}(n=30)$} & \multicolumn{2}{|c|}{ Diabets+S I I (n=53) } \\
\hline & I gr & II gr (+SOPP) & III gr & IV gr (+SOPP) \\
\hline $\mathrm{V}, \mathrm{ml} / \mathrm{min}$ & $0,98 \pm 0,04$ & $2,61 \pm 0,11^{* *}$ & $1,22 \pm 0,03^{*}$ & $3,24 \pm 0,10^{* * *}$ \\
\hline $\mathrm{EFH} 2 \mathrm{O}, \%$ & $0,88 \pm 0,03$ & $2,25 \pm 0,04^{* *}$ & $1,03 \pm 0,02 *$ & $2,70 \pm 0,03 * * *$ \\
\hline GFR, $\mathrm{ml} / \mathrm{min}$ & $112,0 \pm 2,2$ & $116,0 \pm 2,4$ & $118,0 \pm 1,7^{*}$ & $120,0 \pm 1,9$ \\
\hline $\mathrm{PNa}, \mathrm{mmol} / \mathrm{I}$ & $139,0 \pm 1,4$ & $140,0 \pm 1,5$ & $140,0 \pm 1,2$ & $139,0 \pm 1,1$ \\
\hline $\mathrm{PNa} \cdot \mathrm{GFR}, \mathrm{mmol} / \mathrm{min}$ & $15,6 \pm 0,25$ & $16,2 \pm 0,27$ & $16,5 \pm 0,21^{*}$ & $16,7 \pm 0,24$ \\
\hline UNa, mmol / I & $114,0 \pm 3,7$ & $113,0 \pm 3,8$ & $80,0 \pm 3,5^{*}$ & $109,0 \pm 3,6^{* *}$ \\
\hline $\mathrm{UNaV}, \mu \mathrm{mol} / \mathrm{min}$ & $111,7 \pm 3,7$ & $295,0 \pm 9,1^{* *}$ & $97,9 \pm 3,1^{*}$ & $354,2 \pm 6,4 * * *$ \\
\hline $\mathrm{SNa}, \mathrm{ml} / \mathrm{min}$ & $0,80 \pm 0,04$ & $2,10 \pm 0,05^{* *}$ & $0,71 \pm 0,03^{*}$ & $2,55 \pm 0,04^{* * *}$ \\
\hline $\mathrm{EFNa}, \%$ & $0,72 \pm 0,03$ & $1,82 \pm 0,04^{* *}$ & $0,60 \pm 0,02^{*}$ & $2,13 \pm 0,03 * * *$ \\
\hline UNaV / GFR * 100, $\mathrm{mmol} / \mathrm{min}$ & $99,0 \pm 3,1$ & $254,0 \pm 6,9 * *$ & $83,0 \pm 2,9^{*}$ & $296,0 \pm 6,1 * * *$ \\
\hline Clearance of non-sodium water, $\mathrm{ml} / \mathrm{min}$ & $0,18 \pm 0,005$ & $0,51 \pm 0,012^{* *}$ & $0,50 \pm 0,004^{*}$ & $0,69 \pm 0,010^{* * *}$ \\
\hline Rosm, mosm / I & $298,0 \pm 2,1$ & $299,0 \pm 2,3$ & $305,0 \pm 2,0^{*}$ & $307,0 \pm 1,9^{*}$ \\
\hline Uosm mosm / I & $781,0 \pm 21,6$ & $710,0 \pm 25,4^{* *}$ & $808,0 \pm 17,5$ & $754,0 \pm 18,6^{* *}$ \\
\hline UosmV, mkosm / min & $765,0 \pm 21,8$ & $1854,0 \pm 52,9^{* *}$ & $986,0 \pm 18,2^{*}$ & $2443,0 \pm 41,0^{* * *}$ \\
\hline Sosm, $\mathrm{ml} / \mathrm{min}$ & $2,6 \pm 0,08$ & $6,2 \pm 0,19 * *$ & $3,2 \pm 0,07^{*}$ & $7,9 \pm 0,15^{* * *}$ \\
\hline EFosm, \% & $2,3 \pm 0,07$ & $5,4 \pm 0,09 * *$ & $2,7 \pm 0,06^{*}$ & $6,6 \pm 0,08 * * *$ \\
\hline $\begin{array}{c}\text { UosmV / GFR * 100, } \\
\mathrm{mcosm} / \mathrm{min}\end{array}$ & $684,0 \pm 9,4$ & $1598,0 \pm 29,1^{* *}$ & $836,0 \pm 15,0^{*}$ & $2036,0 \pm 27,3^{* * *}$ \\
\hline TcN2O, $\mathrm{ml} / \mathrm{min}$ & $1,6 \pm 0,06$ & $3,6 \pm 0,08^{* *}$ & $1,9 \pm 0,05^{*}$ & $4,7 \pm 0,12^{* * *}$ \\
\hline
\end{tabular}

Note: And 1st and 2nd gr. - Systemic Inflammatory Response Syndrome (SIRS); 3rd and 4th gr. - diabetes mellitus (DM) combined with endogenous intoxication syndrome of purulent-septic genesis (CEI); SOPP - increasing the volume of extracellular space by the Ringer solution; ${ }^{*} / \mathrm{P} \leq 0,05$ - the reliability of the indicators between 1st gr. and 3rd gr., 1st and 4th gr., ${ }^{* *} / P \leq 0.05$ - the reliability of the indicators between $1 \mathrm{st}$ gr. and 3rd gr .; 3rd gr. and 4th gr.

years, established duration of the disease 5-12 years; from anamnesis: correction by diet, regimen, pill hypoglycemic agents, insulin (9\%); was first detected by IDDM (4\%); actual glycemia is $8-16 \mathrm{mmol} / \mathrm{l}$, glycosylated hemoglobin> $7 \%$, transient microalbuminuria (30-300 $\mathrm{mg} /$ day); various clinical manifestations of angiopathy and neuropathy have been registered without significant violations of the functions of the affected organs and systems. The course of IDDM in these patients was complicated by acute surgical infection, after surgical rehabilitation of the center of different localization, caused by the association of aerobic gram-positive and gram-negative flora accompanied by syndrome of endogenous intoxication of purulent-septic genesis on the scale of the cellular-humoral index of intoxication $20-50$ points [8]

All the patients received the proper surgical rehabilitation and comprehensive standard intensive care. The correction of sugar was complied by insulin with glycemia $>10 \mathrm{mmol} / \mathrm{l}$ at hospital. The control group consisted of the patients with Systemic Inflammatory Response Syndrome (SIRS) that responded to ICD-10: non-infective etiology without organ failure - SIRS, ICD-10: R-65.2. The patients were divided into 4 groups: $1^{\text {st }}$ and $2^{\text {nd }}$ groups - control studies (NSCS, $n=30) ; 3^{\text {rd }}$ and $4^{\text {th }}$ groups - CSDI $(n=53)$. The patients of $2^{\text {nd }}$ and $3^{\text {rd }}$ groups were subjected to the study in the fragment of infusion therapy with a small volume load of the Ringer solution at a rate of $3 \mathrm{ml} / \mathrm{kg} / \mathrm{h}$ for three hours, which was envisaged by the program. After increasing the volume of extracellular space (SOPP) with Ringer's solution, the patients were examined in 4 hour interval, taking into account the time of infusion loading. The indicators of values studied in biological environments (urine, plasma of blood) are given in the table [9]. The calculation of student's t-criterion for dependent and independent samples (Excell statistical package) was used for statistical analysis of the study data.

\section{RESULTS AND DISCUSSION}

The combination of diabetes with endogenous intoxication syndrome of purulent-septic genesis is a common pathology of the in-patient departments of the surgical section and intensive care units. The basic means of treatment is the use of infusion solutions. Their action is directed at correction of various mechanisms of support of homeostasis. The realization of the end effect is mediated by the corresponding functions of the kidneys. In particular, volumetric and osmoregulatory functions occupy an integrative position. The table presents the data of their constituents of reflection, fragments of intensive care before and after the application of the Ringer solution in the accepted mode. 
The attention was drawn to the state of the volumetric and osmoregulatory function prior to the use of the Ringer solution (III p., Against control - p.) at the initial stages of the study of patients with CSFEI. The activity of the volumorrhegnal function by the clearance of sodium (release of the volume of extracellular fluid) in patients with CNSEMI was lower by $11 \%(\mathrm{p}<0.05)$ than at the NSCL and did not depend on the filtration fraction of sodium. However, the reabsorbed fraction increased to $99.40 \pm 0.03 \%$ (CWS $-99.28 \pm 0.04 \%, \mathrm{p}<0.05$ ), including due to distal reabsorption, since it received a significant increase in the free-water clearance rate (Tab. I). In this case, the excreted sodium fraction decreased and its excretion calculated on the standardized velocity of glomerular filtration (Tab. I). That is, in the case of TSDGEI, despite the increased filtration loading of the proximal department, the activation of distal transport limits the clearance characteristics of the volumorregulatory function and indicates the level of its depression. However, under these observational conditions, it can be assumed that the osmoregulatory function of the kidneys in patients with CSDI is in the state of activation. Thus, the filtration fraction of osmotically active substances increases to $35.99 \pm 0.59 \mathrm{mos} / \mathrm{min}(33.38 \pm 0.61 \mathrm{mosm} / \mathrm{min}-$ in control, $\mathrm{p}<0.05)$, the reabsorbed fraction decreases, excreta - increases by $17 \%(\mathrm{p}<0.05)$, and purification of blood plasma from osmotically active substances by $26 \%$ above the control parameters $(\mathrm{p}<0.05)$ with an increase $(22 \%, \mathrm{p}<0.05)$ of loading osmotically active substances on active nephrons (Tab. I).

The method of detailing the state of the investigated functions and their compensatory possibilities is the infusion load. The chosen method of loading is sufficiently informative and physiological, since it does not violate the design of infusion therapy at TSDGEI. As for control studies, they are listed in the table $\left(1^{\text {st }}-2^{\text {nd }} \mathrm{gr}\right.$. $)$. According to the clearance characteristics, the isotonic loading of the Ringer solution in the given mode activates volumorregulatory (at $162 \pm 27,1 \% ; \Delta, \mathrm{p}<0,05$ ) and osmoregulatory (at $138 \pm 48,3 \% ; \Delta, \mathrm{p}<0,05)$ kidney function. The regulatory mechanisms ensured a high level of excretory fractions and the functioning of existing nephrons (calculated on the standardized velocity of glomerular filtration) in the range of 2, 3-2, 6 values of the corresponding gradients.

The qualitative characteristics of changes in the values of volumetric and osmoregulatory function of the kidneys with infusion loading of the Ringer solution in patients with CCS and CSDI had the same orientation, but they had different quantitative characteristics. Thus, the activity of the volumorregulatory function of the kidneys (in terms of sodium clearance) in patients with CNSEM increased by $260 \pm 47.8 \%(\Delta, \mathrm{p}<0.05)$ with an increase in the gradient of the excreted fraction and sodium excretion, was based on the standardized velocity of glomerular filtration at 3 , 6 times (2.5-2.6 - in control). Accordingly, the clearance of osmotically active substances increased by $147 \pm 46.9 \%$ $(\Delta, \mathrm{p}<0.05)$ without significant changes in the considered gradients.

\section{CONCLUSIONS}

1. Low-level isotope loads with Ringer's solution initiate the same direction of change in volition indices of the osmoregulatory function of the kidneys in patients with systemic inflammatory response syndrome and diabetes mellitus with complicated endogenous intoxication syndrome of purulent-septic genesis.

2. The starting indices of the volumetric and osmoregulatory function of the kidneys of patients with diabetes mellitus with complicated endogenous intoxication syndrome of purulent-septic genesis are characterized by the values indicated by the inhibition of the volumorregulatory (by the clearance of sodium by $11 \%$, $\mathrm{p}<0,05)$ and the activation of the osmoregulatory osmotically active substances by $23 \%, \mathrm{p}<0.05$ ) renal function.

3. The increasing of volume of the extracellular space with the Ringer solution activates the volumetric and osmoregulatory function of the kidneys, respectively, in patients with systemic inflammatory response syndrome by $162 \%(\Delta, \mathrm{p}<0,05)$ and $138 \%(\Delta, \mathrm{p}<0,05)$, at diabetes mellitus complicated by an endogenous intoxication syndrome of purulent-septic genesis by $260 \%(\Delta, \mathrm{p}<0$, $05)$ and $147 \%(\Delta, \mathrm{p}<0,05)$.

4. The use of isotonic load with the Ringer's solution reveals dissociative hyperreactivity of the volumorregulatory function of the kidneys in relation to the osmoregulatory with combining the diabetes mellitus with the endogenous intoxication syndrome of purulent-septic genesis.

\section{REFERENCES}

1. Chatterjee S., Khunti K., Davies M.J. Type 2 diabetes. Lancet. 2017; 389: 2239-51. https://doi.org/10.1016/50140-6736(17)30058-2

2. Yan Zheng, Sylvia H. Ley, Frank B.Hu. Global aetiology and epidemiology of type 2 diabetes mellitus and its complications. Nature Reviews Endocrinology. 2018; 14: 88-98. doi: 10.1038 / nrendo.2017.151.

3. Kumar A., Sagar P., Kashyap B. et al. Int J Diabetes Dev Ctries 2019; 39: 144. https://doi.org/10.1007/s13410-018-0651-0].

4. Pavliak A. Y., Pyptiuk 0. V. Dynamics of the endotoxicosis indices in patients, suffering extended purulent peritonitis. Klinicheskaia Khirurgiia.. 2018; 85(7):56-59. https://doi.org/10.26779/25221396.2018.07.56

5. Krynytska I., Marushchak M., Birchenko I., et al. Markers of endogenous intoxication in rats with diabetes mellitus combined with carrageenaninduced enterocolitis. Romanian Journal of Diabetes Nutrition and Metabolic Diseases. 2018; 25(4): 399-407.

6. Schepers N.J, Bakker 0.J., Besselink M. G., et al. "Impact of characteristics of organ failure and infected necrosis on mortality in necrotising pancreatitis." 2019; 68: 1044-1051. doi:10.1136/gutjnl-2017-314657

7. Classification and Diagnosis of Diabetes: Standards of Medical Care in Diabetes-2018

8. KonovchukV.M., Andrushhak A.V., Maksymchuk N.0. (patentee). Patent № UA 112508 Ukraine (korysna model) G01N 33/48(2006.01) Sposib otsinky perebihu endohennoi intoksykatsii [Patent № UA 112508 Ukraine (utility model) G01N 33/48(2006.01). The way the course evaluation of endogenous intoxication]. Bulleten, 24. 2016. (Ukrainian)

9. Glanz S. [Biomedical statistics] Per. from English - M., Practice, 1998;459 p. Russian 


\section{LIST OF ABBREVIATIONS}

$V$ - diuresis

EFH2O - an excreted water fraction,

GFR - glomerular filtration rate,

$\mathrm{PNa}$ is the concentration of sodium in the blood plasma,

$\mathrm{PNa} \cdot \mathrm{GFR}$ - sodium filtration fraction,

$\mathrm{UNa}$ - concentration of sodium in urine,

$\mathrm{UNaV}$ - excretion of sodium with urine,

$\mathrm{CNa}$ - the clearance of sodium,

EFNa is an excreted sodium fraction,

UNaV / GFR * 100 - Standardized sodium excretion,

Rosm is the concentration of ODP in plasma,

Uosm is the concentration of ODP in urine,

Uosm $V$ - urinary urinary excretion,

Sosm - clearance OAR,

EFosm - an excised OAP fraction,

UosmV / GFR ${ }^{*} 100$ - standardized EDR excretion,

TcN2O - reabsorption of osmotically free fluid.

The work was performed in accordance with the scientific theme of the "Clinical and experimental substantiation of optimization of methods of prevention and treatment of individual complications in surgical practice and intensive care" (state registration № 0115U002767), HSEI of Ukraine "Bukovyna State Medical University".

\section{ORCID and contributionship:}

Viktor M. Konovchuk - 0000-0003-2451-130X ${ }^{A, D, F}$

Sergiy V. Kushnir - 0000-0002-8238-3142 ${ }^{E}$

Andriy V. Andrushchak - 0000-0002-0320-2383 ${ }^{B}$

Iryna I. Iliuk - 0000-0002-0270-8294 ${ }^{\mathrm{C}}$

Petro V. Moroz - 0000-0002-7131-8863 ${ }^{B}$

Conflicts of interest:

Authors declare no conflict of interest.

\section{CORRESPONDING AUTHOR}

\section{Andriy V. Andrushchak}

HSEl Bukovinian state medical university

tel: +380996112269

e-mail:margaritaassistent@gmail.com

Received: 17.07.2019

Accepted: 04.02.2020

A - Work concept and design, B - Data collection and analysis, C - Responsibility for statistical analysis,

D-Writing the article, $\mathbf{E}$ - Critical review, $\mathbf{F}$ - Final approval of the article 